\title{
Commentary: Size still matters
}

\author{
Anthony L. Estrera, MD, FACS
}

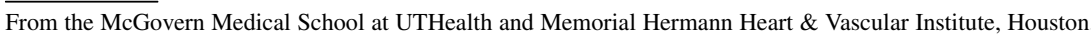
Tex.

Disclosures: Author has nothing to disclose with regard to commercial support.

Received for publication Oct 4, 2018; accepted for publication Oct 4, 2018; available ahead of print Nov 17, 2018. Address for reprints: Anthony L. Estrera, MD, FACS, Department of Cardiothoracic and Vascular Surgery, Mc-

Govern Medical School at UTHealth and Memorial Hermann Heart \& Vascular Institute, 6410 Fannin, Ste 425,

Houston, TX 77030 (E-mail: Anthony.L.Estrera@uth.tmc.edu).

J Thorac Cardiovasc Surg 2019;157:e319

$0022-5223 / \$ 36.00$

Copyright (c) 2018 by The American Association for Thoracic Surgery

https://doi.org/10.1016/j.jtcvs.2018.10.013

Currently, aortic diameter (size) remains the primary indicator that determines intervention for thoracic aortic disease. Much of our knowledge is based on observational work reported nearly 3 decades ago. ${ }^{1}$ As such, we recognize the limitations of using size as the sole determinant for intervention - as many patients who suffer acute aortic dissection present with aortic diameters less than that of the current threshold of $5.5 \mathrm{~cm} .^{2}$

In this issue of the Journal, Ueka and Tsuneyoshi ${ }^{3}$ use computational fluid dynamics (CFD) to analyze the wall sheer stress (WSS) of the dissected aorta. In chronic type $\mathrm{B}$ aortic dissection, the authors provide various examples of high WSS as identified using CFD in the false lumen (Figure 2) as well as in the distal thoracic aorta beyond the stent graft (Figure 3). Importantly, they also present an example of reduced WSS with closure of the fenestration with the stent graft placement (Figure E4).

It must be recognized that the images are only a few examples of how current technology may be applied, but its clinical relevance is yet to be determined. CFD-as a potential modality for predicting late complications after acute aortic dissection-is intriguing but limited by the accuracy of the data entered and the fluctuating conditions not always accounted for by the modeling, as it assumes ideal conditions. The formation of an aneurysm and the initiation of acute aortic dissection occur as an imbalance between the biomaterial properties of the aortic wall and the biomechanical forces applied to the aortic wall. CFD may address the "biomechanical forces" portion of the equation but not the "biomaterials" part. The authors should be encouraged to

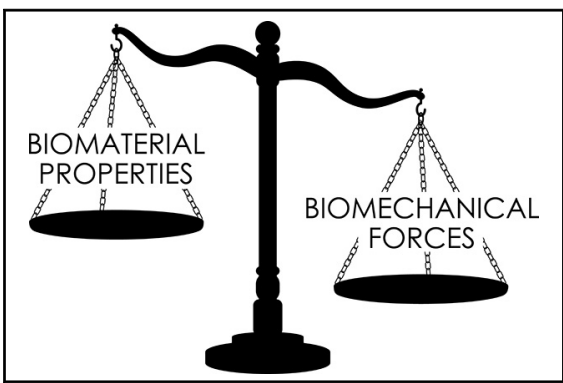

Aneurysm formation and the initiation of acute aortic dissection occurs as an imbalance between the biomaterial properties of the aortic wall and the biomechanical forces applied to the aortic wall.

\section{Central Message}

Although we recognize the limitations of using aortic diameter as the sole determinant for intervention in thoracic aortic disease, until we can better predict acute aortic syndromes before they occur, size still matters.

See Article page e311.

continue this work, as it may expand our overall understanding of the pathobiology of acute aortic dissection. In the meantime-until we are better able to predict acute aortic syndromes before they occur-size still matters.

\section{References}

1. Coady MA, Rizzo JA, Hammond GL, Mandapati D, Darr U, Kopf GS, et al. What is the appropriate size criterion for resection of thoracic aortic aneurysms? J Thorac Cardiovasc Surg. 1997;113:476-91; discussion 489-91.

2. Pape LA, Tsai TT, Isselbacher EM, Oh JK, O'gara PT, Evangelista A, et al. Aortic diameter $>$ or $=5.5 \mathrm{~cm}$ is not a good predictor of type A aortic dissection: observations from the International Registry of Acute Aortic Dissection (IRAD). Circulation. 2007;116:1120-7.

3. Ueka C, Tsuneyoshi H. Late false-lumen expansion predicted by preoperative blood flow simulation in a patient with chronic type B aortic dissection. J Thorac Cardiovasc Surg. 2019;157:e311-7. 